\title{
Lower corneal hysteresis in glaucoma patients with acquired pit of the optic nerve (APON)
}

\author{
Frank Bochmann • Ghee S. Ang • \\ Augusto Azuara-Blanco
}

Received: 24 July 2007 /Revised: 3 December 2007 / Accepted: 13 December 2007 / Published online: 12 January 2008

(C) Springer-Verlag 2007

\begin{abstract}
Objective Acquired pit-like changes of the optic nerve head (APON) are characteristic of glaucomatous damage and may be a sign of a localized susceptibility of the optic nerve. Thus, it is possible that biomechanical properties of the ocular tissues may play a pressure-independent role in the pathogenesis of glaucoma. Corneal hysteresis $(\mathrm{CH})$ appears to provide information of the biomechanical properties of the ocular hull tissues. The purpose of this study was to compare $\mathrm{CH}$ of patients with primary open angle glaucoma (POAG) with and without APON.

Methods A prospective case control study was done. POAG patients with and without APON were measured using the Ocular Response Analyzer by masked investigators. Patients in both groups were matched for sex, age, corneal thickness, and type of glaucoma according to maximal IOP (NTG or POAG). Statistical analysis was done using ANOVA.

Results Corneal hysteresis of 16 glaucomatous eyes with APON and 32 controls (glaucoma without APON) was measured. The mean $( \pm \mathrm{SD}) \mathrm{CH}$ in the APON group was $8.89( \pm 1.53)$ and $10.2( \pm 1.05)$ in the control group. The difference is statistically significant ( $\mathrm{p}=0.005)$.

Conclusions Corneal hysteresis in POAG patients with APON was significantly lower than in patients that did not have such structural changes of the optic disc. These findings may reflect pressure-independent mechanisms
\end{abstract}

F. Bochmann · G. S. Ang · A. Azuara-Blanco

Department of Ophthalmology, Aberdeen Royal Infirmary

and University of Aberdeen,

Aberdeen, UK

F. Bochmann $(\bowtie)$

Department of Ophthalmology, Cantonal Hospital of Lucerne,

6000 Lucerne 16, Switzerland

e-mail: fms.bochmann@bluewin.ch involved in the pathogenesis of such glaucomatous optic nerve changes.

Keywords Corneal hysteresis · Ocular response analyzer . Acquired pit of optic nerve (APON) - Glaucoma

\section{Introduction}

The clinical hallmark of glaucomatous optic neuropathy is the excavation of the tissues of the optic nerve head. This finding distinguishes the glaucomatous optic neuropathy, in which damage to the ganglion cell axons leads to ganglion cell death, from other optic nerve diseases. As these changes are observed even in eyes with high and low intraocular pressure (IOP), biomechanical properties of the lamina cribrosa and susceptibility of the optic nerve head may be involved in the pathogenesis of glaucoma $[1,2]$.

A unique feature of the glaucomatous optic neuropathy is the acquired pit of the optic nerve head (APON), a localised depression of the lamina cribrosa with absent neuroretinal rim tissue localised at superior or inferior rim of the optic disc (Fig. 1). The condition was first described in 1978 [3]. A localized susceptibility of the optic nerve to glaucomatous damage was suggested, as APON predominantly occurs in Normal Tension Glaucoma (NTG) [4]. Additionally, it was suspected that patients with an APON are at a higher risk for progressive optic disk damage [5] and visual field loss close to fixation $[6,7]$.

Corneal hysteresis $(\mathrm{CH})$ is a parameter that provides information of the biomechanical properties of the cornea [8] such as elasticity or damping capacity. The Ocular Response Analyser (ORA) (Reichert, Corp. Buffalo, NY) measures IOP and $\mathrm{CH}$ by assessing the response of the cornea to an air pulse. The air pulse causes an in- and outward movement of 


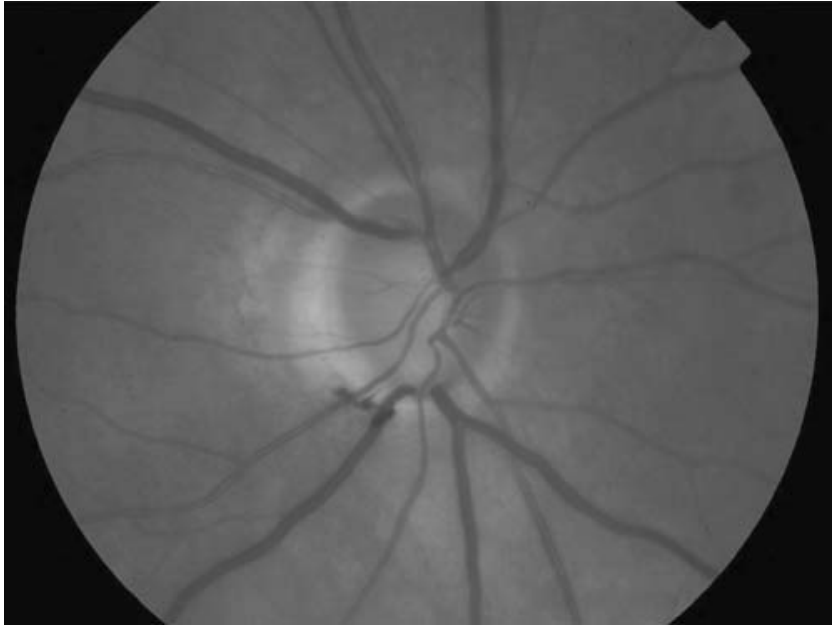

Fig. 1 Inferior acquired pit of optic nerve (APON)

the cornea. During the measurement cycle, the cornea goes through two applanation states, which are detected by an electrooptical collimator. Because the cornea has viscous and elastic properties when stress is temporally applied the tissue recovers its original shape, although the relaxation path is different from the deformation path. The difference in the applied pressure at the two applanation states is named the $\mathrm{CH}$. $\mathrm{CH}$ has been shown to be only moderately correlated to CCT $[8,9]$. The IOP dependence of $\mathrm{CH}$ is minimal.

The aim of this study was to assess whether the biomechanical properties of the corneal tissue of the eye in POAG patients with APONs are different from glaucoma patients without this feature. Such a relationship between biomechanical properties of the cornea and the sclera/ lamina cribrosa would contribute to the growing body of evidence that ocular biomechanics influence the susceptibility of the optic nerve head to glaucomatous damage.

\section{Material and methods}

The protocol of this prospective, observational, cross-sectional study was approved by the local research ethics committee. Adult patients with POAG attending the Glaucoma Clinic of the Aberdeen Royal Infirmary were assessed over a 5-month period, from October 2006 to February 2007.

Patients with POAG with and without APON were consecutively recruited. Primary open-angle glaucoma was defined as an open anterior chamber angle on gonioscopy, reproducible Humphrey SITA 24-2 visual field test abnormality (Humphrey Instruments, San Leandro, California), and a glaucomatous appearance of the optic disc (e.g., generalized or localized thinning of the neuroretinal rim). The exclusion criteria were previous incisional surgery (including cataract surgery), keratorefractive surgery, history of sclera or corneal disease, connective tissue disease, corneal transplantation, contact lens wear and refractive error (i.e., myopia or hyperopia) of $>4$ diopters (D). If both eyes were eligible, the right eye was selected.

Patients with an APON were identified by assessment of the optic nerve head after pupil dilatation with tropicamide $0.5 \%$ eyedrops using a $66 \mathrm{D}$ fundus lens. The patients showed pit-like changes with absent neuroretinal rim at the superior or inferior optic disc margin. $\mathrm{CH}$ was measured using the Ocular Response Analyzer. The observer (FB, BA) was masked for the diagnosis and the ocular findings. Patients were instructed prior to the measurement in detail. The quality of measurement (symmetry and height of the ocular response signal) was assessed and only measurements with good quality (i.e., showing tow high slender peaks that indicate the applanation state of the cornea) were used. If two identical measurements were obtained (identical shape and good quality of the measured curve and a difference of $\mathrm{CH}$ of less than $0.2 \mathrm{mmHg}$ between the two measurements) no further measurements were taken, and the average was used. If there was a difference of $\mathrm{CH}$ of more than $0.2 \mathrm{mmHg}$, then an average of four goodquality measurements was calculated and used for analysis.

CCT data were obtained using an ultrasound pachymeter (Quantel Medical SA, Le Brézet, France).

The highest documented IOP and the IOP at the time of $\mathrm{CH}$ measurement was measured using Goldmann applanation tonometry. One single measurement was taken. Glaucoma patients without APON served as control and were matched for age ( \pm 8 years), gender, highest IOP $( \pm 5 \mathrm{mmHg})$ and CCT $( \pm 30 \mu \mathrm{m})$.

For each patient presenting with an APON two matched controls were selected. The age, gender, type of glaucoma, $\mathrm{CCT}$, spherical equivalent, maximal IOP and $\mathrm{CH}$ were recorded in a database. Comparison of means was performed using the independent $t$-test. To analyse the correlation between $\mathrm{CH}$ and $\mathrm{CCT}$ the Pearson correlation index was calculated. The mean $\mathrm{CH}$ of the APON- and the control group were compared using an ANOVA (SPSS 14.0 sofware for Windows; SPSS Inc.,Chicago, IL).

\section{Results}

$\mathrm{CH}$ was measured in 48 consecutive patients. An APON was observed in 16 patients. Patient characteristics are displayed in Table 1.

All patients were Caucasians. Ten patients of the APON group and 20 patients of the control (without APON) group were females $(62.5 \%)$. The difference between the two groups concerning the mean deviation (MD) and the pattern standard deviation (PSD) was not statistically significant $(\mathrm{p}=0.2$ and $\mathrm{p}=0.3$, respectively). Thirteen of the patients in the APON group and therefore 26 of the patients in the control group had NTG defined by untreated IOP below $21 \mathrm{mmHg}$. 
Table 1 Patient characteristics of patients with APON and the control group

\begin{tabular}{lll}
\hline & Glaucoma patients with APON & Controls (glaucoma without APON) \\
\hline$n$ (female) & $16(10)$ & $32(20)$ \\
Age $( \pm \mathrm{SD})$ & $69( \pm 8.7)$ & $68( \pm 7.8)$ \\
Spherical equivalent in D $( \pm \mathrm{SD})$ & $-0.45( \pm 2.1)$ & $0.12( \pm 1.45)$ \\
CCT in microns $( \pm \mathrm{SD})$ & $545( \pm 36)$ & $540( \pm 28)$ \\
Highest IOP in mmHg $( \pm \mathrm{SD})$ & $19.9( \pm 3.5)$ & $21.6( \pm 4.3)$ \\
IOP in mm Hg at time of measurement of CH & $14.7( \pm 1.8)$ & $15.1( \pm 2.27)$ \\
MD & $-9.98( \pm 7.13)$ & $-7.95( \pm 4.44)$ \\
PSD & $8.17( \pm 3.4)$ & $7.04( \pm 3.92)$ \\
CH in mmHg $( \pm \mathrm{SD})$ & $8.89( \pm 1.53)$ & $10.2( \pm 1.05)$ \\
\hline
\end{tabular}

The $\mathrm{CH}$ finally was significantly higher in the control group (without APON) $10.2( \pm 1.05)$ than in the patients with APON $8.89( \pm 1.53)(\mathrm{p}=0.005)$.

The correlation between CCT and $\mathrm{CH}$ was low ( $\mathrm{r}=$ $0.084)$ and not statistically significant $(\mathrm{p}=0.56)$.

The IOP at time of $\mathrm{CH}$ measurement was $14.7( \pm 1.8)$ in the APON group and $15.1( \pm 2.27)$ in the control group, respectively.The difference was not statistically significant $(\mathrm{p}=0.64)$.

Concerning the number of medications used, the two groups were not different. All patients had at least one medication. The mean number of medications used in the APON-group was $1.43( \pm 0.62)$ and $1.37( \pm 0.60)$ in the control group, respectively. The percentage of patients using prostaglandin eye drops was similar with $81 \%$ in the APON group and $78 \%$ in the control group.

\section{Discussion}

High intraocular pressure (IOP) is an important risk factor for the development and progression of glaucoma [10-12]. In recent years, increasing attention has been focused on how the cornea influences the IOP measurement and it is well established that factors such as central corneal thickness (CCT) affects the IOP reading [13, 14] leading to over- or underestimation of the true IOP in patients with thick or thin corneas, respectively. In addition, it has been shown that a thin cornea is an independent risk factor for development of primary open-angle glaucoma (POAG) in patients with ocular hypertension [15]. However, it is not clear at the moment why and how a thin cornea contributes to the risk of developing glaucoma and it has been proposed, that the cornea, as a part of the hull of the eye, reflects biomechanical properties of other tissues of the eye such as the sclera or the lamina cribrosa that could make the eye susceptible to glaucomatous damage [16]. Other conditions affecting the structural integrity of the globe such as myopia [17] also influence the susceptibility of the optic nerve head to glaucomatous damage. Furthermore, physiologic behaviour of the eye wall seems to be associated with the potential events that lead to optic nerve damage in glaucoma [18]. Therefore it is possible that information of the biomechanical properties of the cornea could contribute to the understanding of the pathophysiology of glaucomatous damage. Currently, it is not possible to access the lamina cribrosa tissue directly to measure its properties in vivo. In addition, we do not know whether the biomechanical properties such as elasticity or resistance to deformation of the lamina cribrosa influence the development of glaucomatous damage at all or whether they are secondary to altered intraocular pressure as it has been suggested by Downs et al. [19]. However, it has been shown that aging alters the mechanical integrity of the lamina cribrosa $[1,20,21]$ and it has also been hypothesised that glaucomatous eyes show a reduced compliance of the lamina cribrosa compared to normal eyes [2]. Lesk et al. demonstrated a direct relationship between CCT, compliance of the lamina cribrosa and neuroretinal rim blood flow [22].

In this study, the correlation between $\mathrm{CCT}$ and $\mathrm{CH}$ was low. Luce found also a poor correlation between CCT and $\mathrm{CH},(\mathrm{r}=0.12)$ [8], but it was moderate in a study by Shah et al. $(\mathrm{r}=0.467)$ [9].

Comparison of $\mathrm{CH}$ with other published data must be done with caution due to the possible differences among populations. It would seem that the $\mathrm{CH}$ of patients with APON was lower than the $\mathrm{CH}$ reported in normal subjects. Laiquzzaman et al. [23] report a mean $\mathrm{CH}$ of $12.2 \mathrm{mmHg}$ and Luce [8] a mean $\mathrm{CH}$ of $9.6 \mathrm{mmHg}$, both data obtained from a healthy, younger population (mean age 39.8 and 28 years, respectively).

The findings in this study also suggest a relationship between biomechanical properties of the cornea and glaucomatous damage to the optic nerve head. Patients with an APON were chosen and the $\mathrm{CH}$ was significantly lower in patients with this localized abnormality of the lamina cribrosa. These results suggest on the one hand that the biomechanical properties measured at the cornea could reflect tissue properties from other ocular hull tissues. On 
the other hand it is possible that $\mathrm{CH}$ may be involved in the pathogenesis of glaucomatous damage to the optic disc. The patients in this study were matched for all known factors that could potentially influence the biomechanical properties of the cornea or the type of glaucoma such as $\mathrm{CCT}$, age, gender, and highest IOP. In addition there was no difference in the severity of the glaucoma (MD and PSD).

The results of this study add to other investigations about APON in which they were associated with a higher risk of progressive optic disc changes [5]. In another recent study a correlation of low $\mathrm{CH}$ and glaucoma progression was found [24]. Most patients in this study (with and without APON) had NTG (13/16). This fact suggests that a low CH may be a pressure independent risk factor for glaucoma and that patients with APON may represent a subgroup of NTG.

Regardless of the fact that the biomechanical properties of the cornea affect IOP measurement directly, our findings support the hypothesis that, at least in some types of glaucoma, $\mathrm{CH}$ could be associated with other characteristics of the ocular hull tissues and therefore might be a marker for a possible increased susceptibility of the optic nerve to glaucomatous damage.

\section{References}

1. Albon J, Purslow PP, Karwatowski WSS, Easty DL (2000) Agerelated compliance of the lamina cribrosa in human eyes. $\mathrm{Br} \mathrm{J}$ Ophthalmol 84:318-323

2. Zeimer RC, Ogura Y (1989) The relation between glaucomatous damage and optic nerve head mechanical compliance. Arch Ophthalmol 107:1232-1234

3. Radius RL, Maumenee AE, Green WE (1978) Pit-like changes of the optic nerve head in open-angle glaucoma. Br J Ophthalmol 62:389-393

4. Javitt JC, Spaeth GL, Katz LJ, Poryzees E, Addiego R (1990) Acquired pits of the optic nerve. Increased prevalence in patients with low tension glaucoma. Ophthalmology 97:1038-1043

5. Ugurlu S, Weitzman M, Nduaguba C, Caprioli J (1998) Acquired pit of the optic nerve: a risk factor for progression of glaucoma. Am J Opththalmol 125:457-464

6. Cashwell LF, Ford JG (1995) Central visual field changes associated with acquired pits of the optic nerve. Opthalmology 102:1270-1278

7. Nduaguba C, Ugurlu S, Caprioli J (1998) Acquired pits of optic nerve in glaucoma: prevalence and associated visual field loss. Acta Ophthalmol Scand 76:273-277

8. Luce DA (2005) Determining in vivo biomechanical properties of the cornea with an ocular response analyzer. J Cataract Refract Surg 31:156-162
9. Shah S, Laiquzzaman M, Cunliffe I, Mantry S (2006) The use of the Reichert ocular response analyser to establish the relationship between oculare hysteresis, corneal resistance factor and central corneal thickness in normal eyes. Contact Lens Anterior Eye 29:257-262

10. Kass MA, Heuer DK, Higginbotham EJ et al (2002) The ocular hypertension treatment study: a randomised trial determines that topical ocular hypotensive medication delays or prevents the onset of primary open-angle glaucoma. Arch Ophthamol 120: 701-713

11. Heijl A, Leske MC, Bengtsson B et al (2002) Early manifest glaucoma trial group. Reduction of intraocular pressure and glaucoma progression: results from the Early Manifest Glaucoma Trial. Arch Ophthalmol 120:1268-1279

12. The AGIS Investigators (2000) The Advanced Glaucoma Intervention Study (AGIS): the relationship between control of intraocular pressure and visual field deterioration. Am J Ophthalmol 130:429-440

13. Doughty MJ, Zaman ML (2000) Human corneal thickness and its impact on intraocular pressure measures: a review and meta analysis approach. Surv Ophthalmol 44:367-408

14. Liu J, Roberts CJ (2005) Influence of corneal biomechanical properties on intraocular pressure measurement: quantitative analysis. J Cataract Refract Surg 31:146-155

15. Gordon MO, Beiser JA, Brandt JD (2002) The ocular hypertension treatment study: baseline factors that predict the onset of primary open-angle glaucoma. Arch Ophthalmol 120:714-720

16. Brown KE, Congdon NG (2006) Corneal structure and biomechanics: impact on the diagnosis and management of glaucoma. Curr Opin Ophthalmol 17:338-343

17. Mitchell P, Hourihan F, Sandbach J, Wang JJ (1999) The relationship between glaucoma and myopia: the Blue Mountains Eye Study. Ophthalmology 106:2010-2015

18. Burgoyne CF, Downs JC, Bellazza AJ, Suh JK, Hart RT (2005) The optic nerve head as a biomechanical structure: a new paradigm for understanding the role for IOP-related stress and strain in the pathophysiology of glaucomatous optic nerve head damage. Prog Retin Eye Res 24:39-73

19. Downs JC, Suh JK, Thomas KA et al (2005) Viscoelastic material properties of the peripapillary sclera in normal and early-glaucoma monkey eyes. Invest Ophthalmol Vis Sci 46:540-546

20. Kotecha A, Elsheikh A, Roberts CT, Zhu H, Garway-Heath DF (2006) Corneal thickness and age-related biomechanical properties of the cornea measured with the ocular response analyser. Invest Ophthalmol Vis Sci 47:5337-5347

21. Kotecha A, Izadi S, Jeffrey G (2006) Age related changes in the thickness of the human lamina cribrosa. Br J Ophthalmol 90:1531-1534

22. Lesk MR, Hafez AS, Descovich D (2006) Relationship between central corneal thickness and changes of optic nerve head topography and blood flow after intraocular pressure reduction in open-angle glaucoma and ocular hypertension. Arch Opththalmol 124:1568-1572

23. Laiquzzaman M, Bohjwani R, Cunliffe I, Shah S (2006) Diurnal variation of ocular hysteresis in normal subjects: relevance in clinical context. Clin Exp Ophthalmol 34:114-118

24. Congdon NG, Broman AT, Bandeen-Roche K, Grover D, Quigley HA (2006) Central corneal thickness and corneal hysteresis associated with glaucoma damage. Am J Ophthalmol 141:868875 